\title{
Tagung über die Konferenz in Rom zur Errichtung eines Ständigen Internationalen Strafgerichtshofes
}

\author{
Von Sonja-Verena Köhler
}

Wenige Tage nach der Verabschiedung des in Rom erarbeiteten Statuts zur Errichtung eines Ständigen Internationalen Strafgerichtshofes fand hierzu vom 23. bis 26. Juli 1998 in Marburg eine Tagung statt, die die örtliche Fakultätsgruppe der European Law Students Association (ELSA) im Rahmen des International Focus Programme "The Law of Peace in the Year 2000" ausrichtete.

Nach einem Überblick über die philosophischen und historischen Wurzeln der Idee eines Weltstrafgerichtshofes erläuterte Professor Dr. Manfred Mohr vom Landesverband des Berliner Roten Kreuzes e.V. und Mitglied der International Association of Lawyers Against Nuclear Arms (IALANA) die Struktur des Statuts. Neben dem "harten Kern" der Delikte Völkermord, Kriegsverbrechen und Verbrechen gegen die Menschlichkeit - fanden die Gründe für das Scheitern einer Aufnahme des Verbrechens der Aggression sowie die im Statut recht unklar gehaltene Definition der Verbrechen gegen die Menschlichkeit besonderes Interesse. Einen Blick hinter die politischen Kulissen der Verhandlungen ermöglichte Hans-Peter Kaul vom Auswärtigen Amt als Leiter der deutschen Delegation in Rom. Wie dort gaben die Fragen der Unterwerfung der jeweiligen souveränen Staaten unter eine neue internationale Gerichtsbarkeit und der Voraussetzungen ihrer Jurisdiktion auch im Fall innerstaatlicher Konflikte den Tagungsteilnehmern reichlich Diskussionsstoff. Professor Dr. Otto Lagodny (Dresden) referierte über die Möglichkeiten für eine Umsetzung des neuen Statuts in das deutsche Recht. Frau Dagmar Stroh vom T.M.C. Asser Institut (Den Haag) grenzte das Statut von demjenigen des Tribunals für das ehemalige Jugoslawien ab. Das Verhältnis der neuen Gerichtsbarkeit zum UN-Sicherheitsrat und insbesondere die damit verbundenen Reibungsflächen behandelte Professor Dr. Roger Clark von der Universität New Jersey. Große Beachtung fanden auch Verfahrensfragen der internationalen Strafgerichtsbarkeit.

Als Höhepunkt und zugleich Abschluß vereinte die Tagung noch einmal die meisten Referenten zu einer Podiumsdiskussion, an der als Gast auch Professor Dr. Otto Trifterer (Universität Salzburg) teilnahm. Die lebhafte Erörterung von Dimensionen und Perspektiven einer künftigen permanenten internationalen Strafgerichtsbarkeit ließ vor allem Genugtuung spüren, mit dem römischen Statut einen wichtigen Schritt in der Entwicklung des humanitären Völkerrechts vorangekommen zu sein. Dennoch: Der praktischen Wirksamkeit 
des neuen Strafgerichtshofes muß erst noch die Ratifizierung des Statuts durch die Staaten und deren vorbehaltlose Bereitschaft zur Kooperation vorangehen. Bis dahin sind noch etliche Hürden zu überwinden, insbesondere in bezug auf die Präzisierung der Straftatbestände und ihrer detaillierten prozeßrechtlichen Umsetzung. Die Vorbereitungskomittees zur prozeßrechtlichen Ausgestaltung sollen Anfang 1999 ihre Arbeit aufnehmen. 